\title{
Anti-Inflammation, Immunomodulation and Therapeutic Repair in Current Clinical Trials for the Management of COVID-19
}

This article was published in the following Dove Press journal:

Drug Design, Development and Therapy

\author{
Chenghai $\operatorname{Li} \mathbb{D}^{1,2, *}$ \\ Hua Zhao ${ }^{3, *}$ \\ Linna Cheng $\mathbb{D}^{4, *}$ \\ Bin Wang ${ }^{5}$
}

'Stem Cell Program of Clinical Research Center, Henan Provincial People's Hospital and People's Hospital of Zhengzhou University, Zhengzhou, 450003, People's Republic of China;

${ }^{2}$ Henan Provincial Engineering Research Center for Immune Cell and Stem Cell

Treatment, Zhengzhou, 450003, People's Republic of China; ${ }^{3}$ Reproductive Medicine Institute, Henan Provincial People's Hospital and People's Hospital of Zhengzhou University, Zhengzhou, 450003, People's Republic of China; ${ }^{4}$ Institute of Hematology, Henan Provincial People's Hospital and People's Hospital of Zhengzhou University, Zhengzhou, 450003, People's Republic of China; ${ }^{5}$ Department of Neurosurgery, Henan Provincial People's Hospital and People's Hospital of Zhengzhou University, Zhengzhou, 450003, People's Republic of China

*These authors contributed equally to this work

\begin{abstract}
The coronavirus disease 2019 (COVID-19), caused by the severe acute respiratory syndrome coronavirus-2 (SARS-CoV-2), continues to spread around the world. While prophylactic vaccines against SARS-CoV-2 are making great progress, there is still a need to explore safe and effective therapies with biological products for COVID-19. Currently clinical trial efforts are planned and ongoing using different biological agents for antiinflammatory therapies, immunomodulation, and therapeutic repair in COVID-19. Targeting inflammatory cytokines with antibodies or inhibitors may be an urgent therapeutic strategy for COVID-19. Importantly, it is critical for an in-depth understanding of these new clinical therapeutic agents in their conditions that are probably involved in both physiological and pathological host responses. In this article, we analyze the potential implications for the current clinical trials of therapeutic biologics and address issues for the development of the COVID-19-related biological therapies.
\end{abstract}

Keywords: COVID-19, cytokine blockade, immunomodulation, therapeutic repair

\section{Introduction}

Severe acute respiratory syndrome coronavirus-2 (SARS-CoV-2) is responsible for coronavirus disease-19 (COVID-19). The increase of COVID-19 cases is of great global concerns. Patients affected by COVID-19 will experience respiratory illness processes and, of note, $26.1 \%$ hospitalized patients require to be treated in the intensive care unit due to pneumonia complications, including $61.1 \%$ with acute respiratory distress syndrome (ARDS) among these hospitalized patients, 44.4\% with arrhythmia and 30.6\% with shock. ${ }^{1}$ COVID-19 also affects different parts of the body with various clinical manifestations. As a novel infectious disease, safe and effective life-saving antiviral drugs to COVID-19 patients are not enough but expedite the development of treatment options. Vaccines are being developed with unprecedented speed but the translational challenges are still numerous. To ensure the latest information that is available, the WHO is publishing a regularly updated list of COVID-19 vaccine candidates in both clinical and pre-clinical development. ${ }^{2}$ Currently, there are 74 candidate vaccines under clinical development and 182 under pre-clinical development. ${ }^{2}$ Owing to safe and effective results from clinical trials, the both Pfizer-BioNTech and Moderna COVID-19 Vaccines are early authorized to prevent COVID-19 in persons aged $\geq 16$ and $\geq 18$ years, respectively, ${ }^{3,4}$ albeit the main question remains about how long the vaccines will
Correspondence: Bin Wang; Chenghai Li Email bin.wang20I166@hotmail.com; chenghai_li@yahoo.com 
protect people from COVID-19. Usually, vaccines are being applied to the prophylaxis early in the course of infectious diseases to prevent poor outcomes. Facing the COVID-19 global pandemic, scientists, physicians and government are urged to rework different strategies to combat this disease. To explore novel therapeutic agents become a prompt treatment option for COVID-19. Clinical trials need to establish safety and effectiveness of therapeutic drugs for the management of COVID-19.

To date, treatment of COVID-19 with biologic agents has drawn increasing attention, reflected in the numerous ongoing and planned clinical trials. While a large and growing body of research has demonstrated that conventional drugs such as Dexamethasone and Ribavirin are partly effective, therapies using biologic agents for COVID-19 are not briefly mentioned. For this reason, the current review focuses mainly on different treatment strategies using a variety of biological agents based on clinical trials registered on the clinicaltrials.gov. Given that a huge effort is being put in the development of biological agents, we will briefly summarize our understanding of such agents as well as comment on their pros and cons for the management of COVID-19. Acknowledging multiple aspects of some therapeutic agents, this review also addresses their potential immuno-pathological complications in COVID-19 infection control for the development of more safe and effective biological therapies. In addition, several therapeutic drugs that are not biologic but closely related to the biological signaling cascade such as Janus kinase (JAK) inhibitor and Rapamycin are also discussed and included to this review.

\section{Currently Clinical Trials of Biological Agents for COVID-I 9}

People all around the world are anxiously awaiting the development of more effective and safe biological therapies for the management of COVID-19. In order to get the latest research information from NIH, we recently performed a search at the clinicaltrials.gov in the present article. We used the key search terms "COVID-19", "antibody/immunoglobulin", "Intravenous immunoglobulin (IVIG)", "cytokine", "growth factor", "antagonist/agonist/inhibitor", "mammalian target of Rapamycin (mTOR)" and "complement" and, after selection, comprehensively enumerated the total of 317 clinical investigations worldwide registered on the clinicaltrials.gov through February 28, 2021 (Table 1). The eligibility criteria for considering a clinical trial included in this review belong to the following categories: a ClinicalTrials Identifier number; the number of participants; a time period; the participants' clinical condition/disease; the nature of intervention/ treatment, contact and location. We roughly categorized the selected investigations into anti-inflammatory and immunomodulatory therapies (282 trials) and therapeutic repair (35 trials) according to the biological agents that are currently being explored. Some of the mentioned therapeutic agents can be ascribed to any of these categories such as JAK inhibitor. Indeed, the issue of separating biological processes is challenging due to the multifaceted roles of these cytokines and growth factors that have been implied within different contexts. We analyzed and assessed their therapeutic potentials and challenges for the treatment and management of patients with COVID-19. Importantly, it would be to quickly determine whether these biological agents are safe and effective in clinical trials. Expectedly, patients with COVID-19 would come forward to take these agents early if clinical data suggest these biologics may be promising.

\section{Anti-Inflammatory and Immunomodulatory Therapies for COVID-19}

Interleukin (IL) Receptor Antibody, Interferon (IFN) and Anti-IFN- $\gamma$, Anti-Tumor Necrosis Factor (TNF) Agent and p-Selectin Antibody

A subset of patients with severe acute COVID-19 pneumonia develop a hyper-inflammatory state, as is shown significant upregulation of a series of mediators including pro-inflammatory cytokines/chemokines. ${ }^{5}$ Some cytokines act as key drivers of COVID-19 pneumonia during the innate immune responses to the SARS-CoV-2. Therefore, targeting cytokine-associated signaling pathway for mitigation of the hyper-inflammatory state could be a therapeutic strategy. Currently, there are certain clinical data available using cytokine antagonists with biological agents for the treatment of COVID-19. One small openlabel study has reported that targeting the inflammatory cascade with Anakinra, a recombinant form of IL-1 receptor antagonist, is a safe and effective approach for the treatment of the moderate to severe COVID-19 pneumonia. ${ }^{6}$ Another open-label and randomized clinical trial demonstrates that Anakinra does not improve outcomes in patients with mild-to-moderate COVID-19 pneumonia. ${ }^{7}$ Interestingly, one trial (NCT04148430) conducted by Memorial Sloan Kettering Cancer Center, New York, is underway to determine whether Anakinra 
Table I Summary of Clinical Trials of Therapeutic Agents for COVID-19 ( $n=317$, as of February 28, 202I)

\begin{tabular}{|c|c|c|c|c|c|c|c|c|c|c|}
\hline Category & \multicolumn{2}{|c|}{$\begin{array}{l}\text { Therapeutic } \\
\text { Agent }\end{array}$} & $\begin{array}{l}\text { No. of } \\
\text { Trials }\end{array}$ & $\begin{array}{l}\text { No. of } \\
\text { Phase I }\end{array}$ & $\begin{array}{l}\text { No. of } \\
\text { Phase I/ } \\
\text { II }\end{array}$ & $\begin{array}{l}\text { No. of } \\
\text { Phase II }\end{array}$ & $\begin{array}{l}\text { No. of } \\
\text { Phase II/ } \\
\text { III }\end{array}$ & $\begin{array}{l}\text { No. of } \\
\text { Phase III }\end{array}$ & $\begin{array}{l}\text { No. of } \\
\text { Phase IV }\end{array}$ & $\begin{array}{l}\text { No. of } \\
\text { Phase N/ } \\
\text { A }\end{array}$ \\
\hline \multirow{22}{*}{$\begin{array}{l}\text { Anti-inflammatory } \\
\text { /Immunomodulation }\end{array}$} & \multicolumn{2}{|c|}{ Anti-IL-IR } & 27 & & & 9 & 4 & 7 & & 7 \\
\hline & \multicolumn{2}{|c|}{ Anti-IL-6R } & 66 & 2 & & 24 & 9 & 19 & 3 & 9 \\
\hline & \multicolumn{2}{|c|}{$\begin{array}{l}\text { Anti-IL-IR and } \\
\text { Anti-IL-6R }\end{array}$} & 3 & & & 2 & & I & & \\
\hline & \multicolumn{2}{|c|}{$\begin{array}{l}\text { Anti-IL-IR and } \\
\text { JAK inhibitor }\end{array}$} & 2 & & & I & & I & & \\
\hline & \multicolumn{2}{|c|}{$\begin{array}{l}\text { Anti-IL-6R and } \\
\text { JAK inhibitor }\end{array}$} & I & & & & & I & & \\
\hline & \multicolumn{2}{|c|}{ Anti-IFN- $\gamma$} & I & & & & I & & & \\
\hline & \multicolumn{2}{|c|}{ Anti-TNF- $\alpha$} & 6 & & & 2 & & 2 & & 2 \\
\hline & \multicolumn{2}{|c|}{ Anti-P-Selectin } & I & & & I & & & & \\
\hline & \multicolumn{2}{|c|}{ JAK inhibitor } & 43 & & 2 & 20 & 6 & 8 & I & 6 \\
\hline & \multicolumn{2}{|c|}{ PD-I blocking } & 5 & & & 5 & & & & \\
\hline & \multicolumn{2}{|c|}{$\begin{array}{l}\text { PD-I blocking } \\
\text { and Anti-IL-6R }\end{array}$} & I & & & I & & & & \\
\hline & \multicolumn{2}{|c|}{ Anti-CCR5 } & 5 & & & 4 & I & & & \\
\hline & \multicolumn{2}{|c|}{$\begin{array}{l}\text { Complement } \\
\text { inhibitor }\end{array}$} & 14 & & I & 7 & & 4 & I & I \\
\hline & \multicolumn{2}{|c|}{$\begin{array}{l}\text { Neutralizing } \\
\mathrm{Ab} \text { and } \mathrm{Ig}\end{array}$} & 59 & 12 & 6 & 13 & 9 & 9 & 3 & 7 \\
\hline & \multicolumn{2}{|l|}{ IL-2 } & I & & & I & & & & \\
\hline & \multirow[t]{3}{*}{ IFN } & IFN- $\alpha$ & 11 & I & I & 2 & I & 2 & I & 3 \\
\hline & & IFN- $\beta$ & 21 & & & 11 & I & 6 & 3 & \\
\hline & & $\mathrm{IFN}-\lambda$ & 5 & & & 5 & & & & \\
\hline & \multicolumn{2}{|c|}{ Anti-IL-I5 } & 2 & I & I & & & & & \\
\hline & \multicolumn{2}{|c|}{ Anti-IL-I7 } & I & & & & & I & & \\
\hline & \multicolumn{2}{|c|}{ Anti-IL-23 } & I & & & I & & & & \\
\hline & \multicolumn{2}{|c|}{$\begin{array}{l}\text { mTOR } \\
\text { inhibitor }\end{array}$} & 6 & I & I & 4 & & & & \\
\hline
\end{tabular}

(Continued) 
Table I (Continued).

\begin{tabular}{|c|c|c|c|c|c|c|c|c|c|}
\hline Category & $\begin{array}{l}\text { Therapeutic } \\
\text { Agent }\end{array}$ & $\begin{array}{l}\text { No. of } \\
\text { Trials }\end{array}$ & $\begin{array}{l}\text { No. of } \\
\text { Phase I }\end{array}$ & $\begin{array}{l}\text { No. of } \\
\text { Phase I/ } \\
\text { II }\end{array}$ & $\begin{array}{l}\text { No. of } \\
\text { Phase II }\end{array}$ & $\begin{array}{l}\text { No. of } \\
\text { Phase II/ } \\
\text { III }\end{array}$ & $\begin{array}{l}\text { No. of } \\
\text { Phase III }\end{array}$ & $\begin{array}{l}\text { No. of } \\
\text { Phase IV }\end{array}$ & $\begin{array}{l}\text { No. of } \\
\text { Phase N/ } \\
\text { A }\end{array}$ \\
\hline \multirow[t]{8}{*}{ Tissue regeneration } & Anti-VEGF & 6 & & & 3 & 1 & & 1 & 1 \\
\hline & VIP & 4 & I & & I & I & & & I \\
\hline & Anti-CTGF & I & & & 1 & & & & \\
\hline & Anti-GM-CSF & 12 & & & 8 & 2 & 2 & & \\
\hline & GM-CSF & 9 & 2 & I & 4 & 1 & & 1 & \\
\hline & PGEI analog & I & & & 1 & & & & \\
\hline & HGF mimetic & I & & & 1 & & & & \\
\hline & EGF & I & I & & & & & & \\
\hline
\end{tabular}

Abbreviations: Ab, antibody; CCR5, C-C chemokine receptor type 5; CTGF, connective tissue growth factor; GM-CSF, granulocyte-macrophage colony-stimulating factor; EGF, epidermal growth factor; HGF, hepatocyte growth factor; IFN, interferon; Ig, immunoglobulin; IL, interleukin; JAK, Janus kinase; N/A, not applicable; PD-I, programmed cell death protein I; PGEI, prostaglandin EI; TNF, tumor necrosis factor; VEGF, vascular endothelial growth factor; VIP, vasoactive intestinal polypeptide.

can prevent the severe side effects caused by CD19specific CAR-T cell therapy in patients with COVID-19. Additionally, two recent clinical studies show that Tocilizumab, a humanized anti-IL-6 receptor monoclonal antibody, has been proposed the safety and efficacy to treat patients with severe and critical COVID-19. ${ }^{8,9}$ However, the mixed results have also been observed in clinical trials with Tocilizumab. ${ }^{10,11}$ For example, a randomized trial involving 249 patients hospitalized in the Tocilizumab group and 128 patients in the placebo group demonstrated that the cumulative percentage of patients who received mechanical ventilation or died by day 28 was $12.0 \%$ in treatment group and $19.3 \%$ in the control, respectively. ${ }^{10}$ Serious adverse events occurred in the $15.2 \%$ of patients receiving Tocilizumab and the $19.7 \%$ of patients receiving a placebo. ${ }^{10}$ Currently, there are two clinical trials with anti-IL-15 (NCT04324996 and NCT04385849), one with anti-IL-17 (NCT04724629), one with anti-IL-23 (NCT04583956), one with anti-IFN- $\gamma$ (NCT04324021), six with anti-TNF- $\alpha$ and one with anti-p-selectin (NCT04435184) to determine the safety and effectiveness for treatment of COVID-19. There are thirty-two clinical trials with type I (eleven with IFN- $\alpha$ and twenty-one with IFN- $\beta$ ) and five with type III (IFN- $\lambda$ subtype) interferons to test their safety and efficacy in the treatment of patients with COVID-19. However, inflammation, on the other hand, is also necessary for tissue-damaged recovery. Several pro-inflammatory cytokines (eg, IL-1, IL-6, IL-8 and TNF- $\alpha$ ) are required in the local to remove virusinfected cells for tissue remodeling, thus facing a doubleedged sword for treatment with targeting cytokineassociated signaling pathway.

\section{JAK Inhibitor}

JAK is a tyrosine kinase family for the downstream signal cascade of type I and II cytokine receptors bound by over 50 bioactive mediators including cytokines, ILs, IFNs, colony-stimulating factors (CSFs) and hormones. ${ }^{12}$ JAK signaling pathways play a key role of cellular proliferation and immune responses. Milara et al have reported that JAK implicates in lung fibrosis in patients with idiopathic pulmonary fibrosis and contributes to alveolar type II (ATII) epithelial cell transformation to mesenchymal transition and fibroblast to myofibroblast. ${ }^{13}$ JAK inhibitors (eg, Baricitinib, Ruxolitinib, and Tofacitinib) can inhibit type I/II cytokine receptors and they are currently being used for the treatment of COVID-19. For example, Baricitinib has now been investigating and is suggested as a promising approach as potential treatment for COVID-19. ${ }^{14-16}$ A recent pilot clinical study reported that treatment with a JAK inhibitor, Ruxolitinib, was shown to be safe in a subgroup of patients with severe COVID-19. ${ }^{17}$ In this study conducted by La Rosée et al, 14 patients with COVID-19 Inflammation Score (CIS) $\geq 10$ of 16 threshold received Ruxolitinib with optimizing therapeutic regimens. ${ }^{17}$ These patients achieving the CIS threshold value of $\geq 10$ showed without clinical signs of 
sepsis and no uncontrolled active infection. The majority of COVID-19 patients presented with progressive hyperinflammation governed by Ruxolitinib and the 4/14 patients indicated the viral clearance. During the early stage of infection, IFNs (type-I IFNs) responses are required to prevent viral replication. As the infection progresses, viruses can develop new strategies to counteract effects of IFNs by targeting JAK signaling pathway. ${ }^{18}$ Additionally, given the hypercoagulability of COVID-19, the potentially increased inherent thrombotic risk associated JAK inhibitor should be alert for the hospitalized patients with COVID-19. ${ }^{19}$ Therefore, JAK inhibitors need to be used cautiously to treat COVID-19.

\section{mTOR Inhibitor}

mTOR is involved in regulating cell metabolism, growth and proliferation, survival, and immunity. Several RNA viruses such as influenza virus, SARS-CoV and Middle East respiratory syndrome coronavirus hijack mTOR pathway to promote their own replication. ${ }^{20}$ An integrative proteo-transcriptomics analysis is performed by Appelberg et al in SARS-CoV-2 infected human hepatocyte-derived cellular carcinoma cell line Huh7 to map the cellular responses. ${ }^{20}$ This study by Appelberg et al ${ }^{20}$ suggests a crosstalk between the SARS-CoV-2 and the Akt/ mTOR/HIF-1 signaling pathway. Attractively, Akt inhibitor MK-2206 can inhibit mTOR signaling pathway, further decreasing virus production in Huh7. However, using mTOR inhibitor Sirolimus failed to block SARS-CoV-2 infection, albeit it was observed to inhibit MERS-CoV in mice. ${ }^{21}$ mTOR inhibitor targeting cell proliferation and suppression of gene expression are being tested in clinical trials. There are six clinical trials for mTOR inhibitors (NCT04341675, NCT04371640, NCT04409327, NCT04461340, NCT04482712, and NCT04584710), as potential treatment options in minimizing the severity of COVID-19.

\section{Neutralizing Monoclonal Antibody/lmmunoglobulin}

Convalescent plasma (CP) therapy appears to have significantly reduced morbidity and mortality in patients with severe and critical COVID-19 when life-threatening illness condition continues to deteriorate. ${ }^{22-24}$ Therapeutic effect of $\mathrm{CP}$ on time to clinical improvement in patients with several and life-threatening COVID-19 was also evaluated in one previous clinical trial conducted by Li et al. ${ }^{25}$ No significant difference was noted between the $\mathrm{CP}$ group and the control group within 28 days. $^{25}$ Therefore, the immediate and urgent challenges have to be addressed at the time of virus outbreak and we would like to extend our discussion in the present paper. First, CP collected from COVID-19 convalescent patients contains a variety of blood-derived components, including nonprotective antibodies/immunoglobulins, complements, clotting factors, cytokines and growth factors, in addition to a large quantity of neutralizing antibodies. ${ }^{26}$ Second, considering that the mutated virus is able to escape the one type of antibody therapy, the emergence of resistant SARS-CoV-2 mutations that may diminish the therapeutic efficacy of neutralizing antibodies needs further attention for the effective treatment options. Third, a potential risk during CP therapy has to be alert on the antibody-dependent enhancement due to cross-reactive antibody responses between SARS-CoV-2 and SARS-CoV infections. ${ }^{27,28}$ Indeed, non-neutralizing antibodies can also bind to the spike glycoprotein on the surface of SARS-CoV-2 to promote virus uptake into host cells via angiotensinconverting enzyme 2 (ACE2) receptor-mediated viral fusion. Fourth, another potential risk is the transfusion immunoglobulin-related acute lung injury, a severe adverse effect of high doses of intravenous immunoglobulin, with high mortality. ${ }^{29}$ Finally, there still exists a potential risk during preparation of anti-SARS-CoV-2 immunoglobulins that needs for viral pathogens inactivation for the safer products. Therefore, CP therapy has safety concerns that still remain under debate.

Immune plasma therapy will be eventually abandoned and replaced by the monoclonal antibody-based therapies. IVIG immunotherapy has been supposed as an efficacious adjuvant with other antiviral drugs in the treatment of COVID-19..$^{30,31}$ SARS-CoV-2-neutralizing monoclonal antibodies and enriched immunoglobulins from $\mathrm{CP}$ have important advantages over the CP. Currently, fifty-nine clinical trials using neutralizing monoclonal antibodies and immunoglobulins are being performed in combating SARS-CoV-2 infections. Among these, two clinical studies are exemplified as representing new immunotherapeutic approaches. One study (NCT04342195) conducted by Columbia University, New York, is still ongoing to utilize blood specimens from patients who have recovered from COVID-19 infection for isolation of specific monoclonal antibodies from human B cells to potently neutralize the SARSCoV-2. Purified antibodies will be further assessed using neutralization assays to determine the therapeutic potential of antiSARS-CoV-2. Another one (NCT04354766) has been conducting to generate human monoclonal antibodies neutralizing SARS-CoV-2 from convalescent patients and antibody 
neutralizing capacities would be evaluated among the COVID19 convalescent donors. Double-filtration plasmapheresis (DFPP), an extracorporeal blood purification technique to reduce hepatitis C viral RNA, is also used to efficiently collect antibodies from COVID-19 convalescent patients (NCT04346589 and NCT04418531). Indianapolis, Eli Lilly and Company announced on June 1, 2020, that patients had been dosed in the world's first study of neutralizing IgG1 monoclonal antibody treatment specifically designed to fight COVID-19. ${ }^{32}$ Using combination of antibodies (antibody cocktails), a theoretical treatment strategy, may enhance potential therapeutic efficiency. Antibody cocktail approaches have shown substantial promise in recent in vitro and in vivo studies for preventing SARS-CoV-2 escape. ${ }^{33,34}$ Of special notes, one double-blind and Phase I-III trial suggests that an antibody cocktail against SARS-CoV-2 is safe and effective in an individual patient whose immune response has not yet been initiated. ${ }^{35}$ Currently, there are eleven ongoing trials (NCT04381936, NCT04425629, NCT04426695, NCT04452318, NCT04519437, NCT04617535, NCT04634409, NCT04666441, NCT04691180, NCT04700163 and NCT04770467) using the synergistic neutralizing antibody cocktails in COVID-19 patients.

\section{Complement Inhibitor/Blockade}

Whilst the precise mechanisms of action are unclear, antibodies function as the direct antivirus by the antibody-mediated immunomodulatory processes, including agglutination of virus, opsonization, viral and toxin neutralization. Complement is involved in the immunomodulatory processes. Complement is also a major component of the innate immune system in host that functions to defense against bacterial and viral infection and to maintain immune homeostasis. Excessive complement activation in the lung may contribute to pathologic outcomes. ${ }^{36}$ Gralinski et al previously observed that complement component $\mathrm{C} 3$ activation in the lung initiated as early as day one following SARS-CoV infection in a $\mathrm{C}^{-/-}$animal model and $\mathrm{C}^{-/-}$mice exhibited significantly less respiratory dysfunction. ${ }^{37}$ Jiang et al reported in a previous study that the concentration of C5a was increased in sera and lung tissues in MERS-CoV-infected hDPP4-transgenic mice and the blockade of the C5aC5aR axis with a specific complementary antibody alleviated lung damage. ${ }^{38}$ Potential complement component inhibitors with biological agents are currently being tested in patients with COVID-19. One recent clinical study using the combination of an anti-C5a monoclonal antibody (Eculizumab) and a JAK1/2 inhibitor
(Ruxolitinib) revealed significant improvement in patients with severe SARS-CoV-2-related ARDS. ${ }^{39}$ Another recent investigation indicated Eculizumab, a well-established safety profile, combined with antiviral drugs might work as a therapeutic option for the treatment of patients with severe COVID-19. ${ }^{40}$ These safe data collected from clinical studies will support complement inhibition therapeutic potential in treating COVID-19.

\section{Programmed Cell Death Protein I (PD-I) and C-C Chemokine Receptor Type 5 (CCR5) Antagonist}

PD-1 is often expressed in immune cells including lymphocytes, natural killer cells, and dendritic cells and upregulation of PD-1/PD-1 ligands is generally observed during acute virus infection. ${ }^{41} \mathrm{~T}$ cells from COVID-19 patients have significantly higher levels of PD-1 during the disease progress. ${ }^{42}$ Currently ongoing clinical trials of PD-1 blockade (eg, Nivolumab and Pembrolizumab) have also been performing for treatment of patients with COVID-19. Chemokines act as chemo-attractants in the inflammatory cell recruitment during SARS-CoV-2 infection. The chemokine CCL3 and CCL4 are significantly up-regulated in the plasma of COVID-19 patients with a cytokine storm syndrome state compared to healthy controls. ${ }^{5}$ Blockade of the CCR5 (receptor for CCL3 and CCL4) with biological agents is proposed. There are currently five initiating clinical trials (NCT04343651, NCT04347239, NCT04475991, NCT04678830 and NCT04710199) to determine whether the CCR5 antagonists Leronlimab and Maraviroc as therapeutic agents work against COVID19. It would be good to see the beneficial effects on COVID-19.

As aforementioned, a central unanswered question concerns the right timing of administration that is critical and needs to be determined in clinical trials. Currently, the immunopathology of SARS-CoV-2 infection is becoming clearer. There are three stages of the infection's progression, as is recognized as the mild, moderate and severe symptoms in COVID-19 patients, and the optimal times for therapeutic interventions are proposed. ${ }^{43}$ Theoretically, cytokine monoclonal antibodies/inhibitors such as JAK inhibitors might be given quickly once the COVID-19 symptoms appear. Thus, assessing clinical progression is urgently needed. 


\section{Therapeutic Repair}

Vascular Endothelial Growth Factor (VEGF)

Antagonist, Vasoactive Agent, and Prostaglandin E (PGE)

Tissue repair and regeneration is a complex process involving a variety of bioactive molecules and enzymes such as VEGF and matrix metalloproteinases. ${ }^{44}$ VEGF is known as a key vascular permeability inducer to increase pulmonary edema during infection. VEGF is also involved in the activation of coagulation pathways in severe COVID-19 probably through triggering endothelial cells to upregulate the expression of tissue factor, ${ }^{45}$ a potent activator of the extrinsic blood coagulation cascade. Therefore, VEGF is considered as a potential therapeutic target to counteract vessel-permeabilizing effect in the early onset of COVID19 to reduce the disease severity. Yuksel et al have reported that VEGF antagonist (Bevacizumab) restores epithelial barrier dysfunction in an experimental asthma model. ${ }^{46}$ A recent clinical study with Bevacizumab showed therapeutic efficacy by improving oxygenation and shortening oxygen-support duration in patients with severe COVID-19. ${ }^{47}$ Likewise, Thalidomide, another angiogenesis inhibitor, has anti-inflammatory and antifibrotic effects and is also used for treatment of COVID19 (NCT04273529 and NCT04273581). Two recent clinical studies suggested Thalidomide combined with lowdose short-term glucocorticoid as an effective therapeutic option in patients with severe COVID-19. ${ }^{48,49}$ However, FDA has warned about life-threatening birth defects caused by Thalidomide and risk of blood clots. ${ }^{50}$

VEGF, on the other hand, is essential for the vascular formation and remodeling and critical for restoration of lung homeostasis. A previous study conducted by McClendon et al showed that VEGF signaling may mediate the role of hypoxia-inducible factor in ATII cell proliferation and spreading, the critical stages necessary to restore epithelial structure and function after lung injury. ${ }^{51}$ Thus, whether VEGF promotes lung therapeutic repair or exacerbates pulmonary edema remains controversial. The immuno-pathological complications need to be considered cautiously. In addition, four clinical trials (NCT04311697, NCT04360096, NCT04453839, and NCT04536350) describe that Aviptadil, a vasoactive intestinal polypeptide, may restore barrier function at the endothelial/alveolar interface, thus protecting the lung from failure. Alprostadil, a PGE1 analog, is a potent vasodilator agent that increases peripheral blood flow. ${ }^{52}$ One Phase II clinical trial (NCT04536363) is ongoing to evaluate the safety and effectiveness of the administration of intravenous PGE1. Although PGE1 may cause bronchodilation and possibly decrease platelet aggregation and intrapulmonary polymorphonuclear leukocyte sequestration for antiinflammatory treatment and tissue modeling in patients with ARDS, there is an increase in the rate of significant adverse events. ${ }^{53,54}$ Together, while some cytokines are responsible to the SARS-CoV-2 infection to play a dual role, it is important to quickly determine whether the potential benefits outweigh the potential risks. Therefore, the plasticity of these therapeutic agents for treatment should be used with great caution.

\section{Connective Tissue Growth Factor (CTGF) Antibody} and Hepatocyte Growth Factor (HGF)

CTGF is a secreted glycoprotein, which has been shown to play a role in the chronic process of fibrosis. ${ }^{55}$ SARS-CoV -2 infection updates CTGF gene expression in human lung epithelial cells, which may promote lung fibrosis in COVID-19 patients. ${ }^{56}$ Anti-CTGF may prevent this cascade. Luca Richeldi et al previously reported the safety and effectiveness of Pamrevlumab, a human monoclonal antibody against CTGF, in patients with idiopathic pulmonary fibrosis. ${ }^{55}$ Currently, one phase II clinical trial (NCT04432298) using Pamrevlumab has been conducting for treatment and management of patients with COVID19. Additionally, HGF has been demonstrated to have a potential role for hastening alveolar repair in patients with acute lung injury (ALI)/ARDS. ${ }^{57}$ This in vitro study by Ito et al using primary human alveolar epithelial cells in wound-healing assay shows that HGF released mainly from lung fibroblasts can promote wound closure by accelerating cell motility. Currently, one clinical trial (NCT04459676) of biologics ANG-377, a small molecule HGF mimetic, is already underway to assess its clinical safety and efficacy in the severity and progression of pulmonary and renal dysfunction in patients hospitalized with COVID-19 pneumonia.

\section{Granulocyte-Macrophage CSF (GM-CSF), Granulocyte-CSF (G-CSF) and GM-CSF Monoclonal Antibody}

Cytokines are central to the immunopathology of COVID19 and some play a dual role, as is shown that they may confer detriment and benefit to patients with COVID-19 pneumonia complications. GM-CSF and G-CSF act as the pro-inflammatory cytokine that partially contributes to a hyper-inflammatory state. ${ }^{5}$ Mechanistically, downstream signaling cascades of GM-CSF are induced through JAK2 
Table 2 Summary of Results of Completed Studies with Therapeutic Agents for COVID-19

\begin{tabular}{|c|c|c|c|c|}
\hline Agent Category & Agent Name & Study Category & Therapeutic Effect & Reference \\
\hline \multirow[t]{4}{*}{ Anti-IL-IR } & Anakinra & Retrospective cohort study & Safety and efficacy & [67] \\
\hline & Anakinra & $\begin{array}{l}\text { Randomized and controlled } \\
\text { trial }\end{array}$ & Safety and efficacy & [68] \\
\hline & Anakinra & $\begin{array}{l}\text { Randomized and controlled } \\
\text { trial }\end{array}$ & Ineffectiveness & [7] \\
\hline & Canakinumab & Cohort controlled trial & Safety and efficacy & [69] \\
\hline \multirow[t]{3}{*}{ Anti-IL-6R } & Tocilizumab & Retrospective study & Safety and effectiveness & [8] \\
\hline & Tocilizumab & $\begin{array}{l}\text { Randomized and controlled } \\
\text { trial }\end{array}$ & Mixed clinical results & {$[10,11]$} \\
\hline & Tocilizumab & $\begin{array}{l}\text { Randomized and controlled } \\
\text { trial }\end{array}$ & Improvement of clinical outcomes & {$[70]$} \\
\hline \multirow[t]{3}{*}{ Interferon } & Peginterferon lambda & $\begin{array}{l}\text { Randomized and controlled } \\
\text { trial }\end{array}$ & Accelerated viral decline & {$[7 I]$} \\
\hline & IFN- $\alpha /$ Ribavirin & Retrospective study & Mixed clinical results & {$[72]$} \\
\hline & $\begin{array}{l}\text { IFN- } \beta \text { I/Lopinavir- } \\
\text { Ritonavir }\end{array}$ & Cohort controlled study & $\begin{array}{l}\text { Safety and improvement of clinical } \\
\text { outcomes }\end{array}$ & [73] \\
\hline \multirow[t]{4}{*}{ JAK inhibitor } & Baricitinib & $\begin{array}{l}\text { Randomized and controlled } \\
\text { trial }\end{array}$ & Improvement of clinical outcomes & {$[16]$} \\
\hline & Baricitinib & Cohort controlled trial & Decreased SARS-CoV-2 infection & [74] \\
\hline & Ruxolitinib & Cohort controlled trial & Safety and effectiveness & {$[17]$} \\
\hline & $\begin{array}{l}\text { Ruxolitinib+ } \\
\text { Anakinra }\end{array}$ & Randomized cohort study & Safety and effectiveness & {$[75]$} \\
\hline \multirow[t]{4}{*}{ Monoclonal Ab } & ChAdOxI nCoV-19 & $\begin{array}{l}\text { Randomized and controlled } \\
\text { trial }\end{array}$ & Safety and efficacy & {$[76]$} \\
\hline & CoronaVac & $\begin{array}{l}\text { Randomized and controlled } \\
\text { trial }\end{array}$ & Safety and efficacy & [77] \\
\hline & SCB-2019 & $\begin{array}{l}\text { Randomized and controlled } \\
\text { trial }\end{array}$ & Safety and efficacy & [78] \\
\hline & LY-CoV555 & Phase II trial & Safety and efficacy & [79] \\
\hline Ab cocktail & REGN-COV2 & Phase I-III trial & Safety and effectiveness & [35] \\
\hline \multirow{3}{*}{$\begin{array}{l}\text { Complement } \\
\text { inhibitor }\end{array}$} & Eculizumab & Pilot clinical trial & Improvements of clinical outcomes & [39] \\
\hline & Eculizumab & Phase $1 / l l$ cohort trial & Safety and effectiveness & {$[80]$} \\
\hline & AMY-10I & Cohort controlled trial & Safety and effectiveness & {$[80]$} \\
\hline Anti-VEGF & Bevacizumab & $\begin{array}{l}\text { Randomized and controlled } \\
\text { trial }\end{array}$ & Safety and effectiveness & [47] \\
\hline Anti-GM-CSF & Lenzilumab & $\begin{array}{l}\text { Randomized and controlled } \\
\text { trial }\end{array}$ & $\begin{array}{l}\text { Safety and improvement of clinical } \\
\text { outcomes }\end{array}$ & {$[60]$} \\
\hline
\end{tabular}

Abbreviations: Ab, antibody; GM-CSF, granulocyte-macrophage colony-stimulating factor; IL, interleukin; JAK, Janus kinase; VEGF, vascular endothelial growth factor. 
pathway, which acts on various downstream cytokines. ${ }^{58}$ In this regard, targeting GM-CSF may mitigate the hyperinflammatory state for curbing lung damage. One recent single-centre prospective cohort clinical study showed that administration of Mavrilimumab, an anti-GM-CSF monoclonal antibody, improved clinical outcomes in thirteen nonmechanically ventilated patients with COVID-19 pneumonia and hyperinflammation. ${ }^{59}$ Another randomized, placebo-controlled clinical trial demonstrated that Lenzilumab, another anti-GM-CSF monoclonal antibody, was safe and effective for the treatment of severe COVID$19 .^{60}$ Currently, there are twelve clinical trials underway to explore a novel approach for the treatment of COVID-19 through targeting of human GM-CSF.

Conversely, GM-CSF, a critical homeostatic factor in lung alveoli, is required in alveolar macrophage homeostasis and lung pathogen clearance to maintain pulmonary function. ${ }^{61,62}$ Detailed studies have demonstrated that GMCSF has been shown to be protective in different preclinical models of pneumonia-associated lung injury and, as compassionate treatment, to improve oxygenation and lung repair in six patients with pneumonia-associated ARDS. ${ }^{63}$ Previous investigation demonstrated GM-CSF involvement in lung surfactant homeostasis in GM-CSF-deficient mice. ${ }^{64}$ Given the mechanism of action of GM-CSF on neutrophils accumulation in the lung, acute lung injury has been reported in a patient with significant pulmonary comorbidities following the use of GM-CSF. ${ }^{65}$ Therefore, monitoring of this immuno-pathological complication together the viral infection progression will be needed with GM-CSF administration in the COVID-19 therapeutic setting. Currently, nine clinical studies using GM-CSF have been performing for prevention and treatment of COVID-19.

Given the immunomodulatory and tissue regenerative properties of mesenchymal stem cells (MSCs), they can secrete a variety of cytokines and growth factors (eg, HGF) and such cells could be used as biological agents for treatment and management of patients with COVID-19 at the time of virus outbreak. Currently, clinical trials using MSCs products as a therapeutic option are ongoing worldwide but potential challenges are numerous. In our recent Commentary to the Drug Design, Development and Therapy, a few important facets, including MSCs fate after systemic infusion, safety issue, MSCs homing and MSCs resistance to the disease microenvironment, would be critically analyzed and addressed for the development of the more safe and effective MSC-based approaches for COVID-19. ${ }^{66}$

\section{Conclusions and Perspectives}

There are more and more clinical trials that are being conducted with biological therapeutic agents for treatment and management of patients with COVID-19. Controlled trials of biological agents are needed to determine their safety and effectiveness for therapeutic perspectives. To help speed the clinical research, the data collected in the present study from current clinical studies may contribute to a better understanding of the mechanisms of action of the biological therapeutic agents. Recently published studies have shown that some therapeutic agents play both pathological and beneficial roles in the management of patients with COVID19 and mixed results have also been obtained in these completed COVID-19 clinical trials (Table 2). We appreciate these clinical trial efforts currently underway for different aspects of COVID-19. While clinical improvement in COVID-19 is the primary outcome measure in most clinical trials of biologics, additional work needs to address safety- and efficacy-related matters in large studies for optimum clinical outcomes. The bottom line is that biological therapeutic agents appear to be safe and clinical efficacy is required more studies. We hope that more and more favorable outcomes of ongoing clinical trials are expected to be observed as quickly as possible.

\section{Acknowledgments}

This work was supported by Henan Provincial Engineering Research Center for Immune Cell and Stem Cell Treatment, China and Henan Key Laboratory of Stem Cell Differentiation and Modification, China.

\section{Author Contributions}

All authors made a significant contribution to the work reported, whether that is in the conception, study design, execution, acquisition of data, analysis and interpretation, or in all these areas; took part in drafting, revising or critically reviewing the article; gave final approval of the version to be published; have agreed on the journal to which the article has been submitted; and agree to be accountable for all aspects of the work.

\section{Disclosure}

The authors declare no conflicts of interests in this work. 


\section{References}

1. Wang D, Hu B, Hu C, et al. Clinical characteristics of 138 hospitalized patients with 2019 novel coronavirus-infected pneumonia in Wuhan, China. JAMA. 2020;323:1061-1069. doi:10.1001/ jama.2020.1585

2. World Health Organization. Draft landscape and tracker of COVID-19 candidate vaccine. Available from: https://www.who.int/ publications $/ \mathrm{m} / \mathrm{item} / \mathrm{draft}$-landscape-of-covid-19-candidate-vaccines. Accessed March 19, 2021.

3. Oliver SE, Gargano JW, Marin M, et al. The Advisory Committee on Immunization Practices' interim recommendation for use of PfizerBioNTech COVID-19 vaccine - United States. MMWR Morb Mortal Wkly Rep. 2020;69:1922-1924. doi:10.15585/mmwr.mm6950e2

4. Oliver SE, Gargano JW, Marin M, et al. The Advisory Committee on Immunization Practices' interim recommendation for use of Moderna COVID-19 vaccine - United States, December 2020. MMWR Morb Mortal Wkly Rep. 2021;69:1653-1656. doi:10.15585/mmwr. mm695152e1

5. Huang C, Wang Y, Li X, et al. Clinical features of patients infected with 2019 novel coronavirus in Wuhan, China. Lancet. 2020;395:497-506. doi:10.1016/S0140-6736(20)30183-5

6. Aouba A, Baldolli A, Geffray L, et al. Targeting the inflammatory cascade with anakinra in moderate to severe COVID-19 pneumonia: case series. Ann Rheum Dis Month. 2020;79:1381-1382. doi:10.1136/ annrheumdis-2020-217706

7. The CORIMUNO-19 Collaborative group. Effect of anakinra versus usual care in adults in hospital with COVID-19 and mild-to-moderate pneumonia (CORIMUNO-ANA-1): a randomised controlled trial. Lancet Respir Med. 2021. doi:10.1016/S2213-2600(20)30556-7

8. Xu X, Han M, Li T, et al. Effective treatment of severe COVID-19 patients with tocilizumab. Proc Natl Acad Sci USA. 2020;117:10970-10975. doi:10.1073/pnas.2005615117

9. Rossotti R, Travi G, Ughi N, et al. Safety and efficacy of anti-IL6receptor tocilizumab use in severe and critical patients affected by coronavirus disease 2019: a comparative analysis. J Infect. 2020;81: e11-e17. doi:10.1016/j.jinf.2020.07.008

10. Salama C, Han J, Yau L, et al. Tocilizumab in patients hospitalized with Covid-19 pneumonia. $N$ Engl $J$ Med. 2021;384:20-30. doi:10.1056/NEJMoa2030340

11. Stone JH, Frigault MJ, Serling-Boyd NJ, et al. Efficacy of Tocilizumab in patients hospitalized with Covid-19. N Engl J Med. 2020;383:2333-2344. doi:10.1056/NEJMoa2028836

12. Schwartz DM, Kanno Y, Villarino A, Ward M, Gadina M, O'Shea JJ. JAK inhibition as a therapeutic strategy for immune and inflammatory diseases. Nat Rev Drug Discov. 2017;16:843-862. doi:10.1038/ nrd.2017.201

13. Milara J, Hernandez G, Ballester B, et al. The JAK2 pathway is activated in idiopathic pulmonary fibrosis. Respir Res. 2018;19:24. doi:10.1186/s12931-018-0728-9

14. Richdson P, Griffin I, Tucker C, et al. Baricitinib as potential treatment for 2019-nCoV acute respiratory disease. Lancet. 2020;395: e30-e31. doi:10.1016/S0140-6736(20)30304-4

15. Stebbing J, Phelan A, Griffin I, et al. COVID-19: combining antiviral and anti-inflammatory treatment. Lancet Infect Dis. 2020;20:400-402. doi:10.1016/S1473-3099(20)30132-8

16. Kalil AC, Patterson TF, Mehta AK, et al. Baricitinib plus remdesivir for hospitalized adults with Covid-19. N Engl J Med. 2020. doi:10.1056/NEJMoa2031994

17. La Rosée F, Bremer HC, Gehrke I, et al. The Janus kinase $1 / 2$ inhibitor ruxolitinib in COVID-19 with severe systemic hyperinflammation. Leukemia. 2020;34:1805-1815. doi:10.1038/ s41375-020-0891-0

18. Favalli EG, Biggioggero M, Maioli G, Caporali R. Baricitinib for COVID-19: a suitable treatment? Lancet Infect Dis. 2020;20:1012-1013. doi:10.1016/S1473-3099(20)30262-0
19. Mehta P, Ciurtin C, Scully M, Levi M, Chambers RC. JAK inhibitors in COVID-19: need for vigilance regarding increased inherent thrombotic risk. Eur Respir J. 2020;56:2001919.

20. Appelberg S, Gupta S, Svensson Akusjärvi S, et al. Dysregulation in Akt/mTOR/HIF-1 signaling identified by proteo-transcriptomics of SARS-CoV-2 infected cells. Emerg Microbes Infect. 2020;9:1748-1760. doi:10.1080/22221751.2020.1799723

21. Kindrachuk J, Ork B, Hart BJ, et al. Antiviral potential of ERK/ MAPK and PI3K/AKT/mTOR signaling modulation for Middle East respiratory syndrome coronavirus infection as identified by temporal kinome analysis. Antimicrob Agents Chemother. 2015;59:1088-1099. doi:10.1128/AAC.03659-14

22. Duan K, Liu B, Li C, et al. Effectiveness of convalescent plasma therapy in severe COVID-19 patients. Proc Natl Acad Sci USA. 2020;117:9490-9496. doi:10.1073/pnas.2004168117

23. Xia X, Li K, Wu L, et al. Improved clinical symptoms and mortality on severe/critical COVID-19 patients utilizing convalescent plasma transfusion. Blood. 2020;136:755-759. doi:10.1182/ blood.2020007079

24. Hegerova L, Gooley TA, Sweerus KA, et al. Use of convalescent plasma in hospitalized patients with COVID-19: case series. Blood. 2020;136:759-762. doi:10.1182/blood.2020006964

25. Li L, Zhang W, Hu Y, et al. Effect of convalescent plasma therapy on time to clinical improvement in patients with severe and life-threatening COVID-19: a randomized clinical trial. JAMA. 2020;324:460-470. doi:10.1001/jama.2020.10044

26. Rojas M, Rodríguez Y, Monsalve DM, et al. Convalescent plasma in Covid-19: possible mechanisms of action. Autoimmun Rev. 2020;19:102554. doi:10.1016/j.autrev.2020.102554

27. Lv H, Wu NC, Tsang OT, et al. Cross-reactive antibody response between SARS-CoV-2 and SARS-CoV infections. Cell Rep. 2020;31:107725. doi:10.1016/j.celrep.2020.107725

28. Iwasaki A, Yang Y. The potential danger of suboptimal antibody responses in COVID-19. Nat Rev Immunol. 2020;20:339-341. doi:10.1038/s41577-020-0321-6

29. Alijotas-Reig J, Esteve-Valverde E, Belizna C, et al. Immunomodulatory therapy for the management of severe COVID-19. Beyond the anti-viral therapy: a comprehensive review. Autoimmun Rev. 2020;19:102569. doi:10.1016/j.autrev.2020.102569

30. Raman RS, Barge VB, Darivenula AK, et al. A phase II safety and efficacy study on prognosis of moderate pneumonia in COVID-19 patients with regular intravenous immunoglobulin therapy. $J$ Infect Dis. 2021. doi:10.1093/infdis/jiab098

31. Shao Z, Feng Y, Zhong L, et al. Clinical efficacy of intravenous immunoglobulin therapy in critical ill patients with COVID-19: a multicenter retrospective cohort study. Clin Transl Immunol. 2020;9:e1192. doi:10.1002/cti2.1192

32. Lilly. Lilly begins world's first study of a potential COVID-19 antibody treatment in humans. Available from: https://investor.lilly.com/ news-releases/news-release-details/lilly-begins-worlds-first-studypotential-covid-19-antibody. Accessed March 19, 2021.

33. Ku Z, Xie X, Davidson E, et al. Molecular determinants and mechanism for antibody cocktail preventing SARS-CoV-2 escape. Nat Commun. 2021;12:469. doi:10.1038/s41467-020-20789-7

34. Zhang C, Wang Y, Zhu Y, et al. Development and structural basis of a two-MAb cocktail for treating SARS-CoV-2 infections. Nat Commun. 2021;12:264. doi:10.1038/s41467-020-20465-w

35. Weinreich DM, Sivapalasingam S, Norton T, et al. REGN-COV2, a neutralizing antibody cocktail, in outpatients with Covid-19. N Eng J Med. 2021;384:238-251.

36. Risitano AM, Mastellos DC, Huber-Lang M, et al. Complement as a target in COVID-19? Nat Rev Immunol. 2020;20:343-344. doi:10.1038/s41577-020-0320-7

37. Gralinski LE, Sheahan TP, Morrison TE, et al. Complement activation contributes to severe acute respiratory syndrome coronavirus pathogenesis. mBio. 2018;9:e01753. doi:10.1128/mBio.01753-18 
38. Jiang Y, Zhao G, Song N, et al. Blockade of the C5a-C5aR axis alleviated lung damage in hDPP4-transgenic mice infected with MERS-CoV. Emerg Microbes Infect. 2018;7:77. doi:10.1038/ s41426-018-0063-8

39. Giudice V, Pagliano P, Vatrella A, et al. Combination of Ruxolitinib and Eculizumab for treatment of severe SARS-CoV-2-related acute respiratory distress syndrome: a controlled study. Front Pharmacol. 2020;11:857. doi:10.3389/fphar.2020.00857

40. Diurno F, Numis FG, Porta G, et al. Eculizumab treatment in patients with COVID-19: preliminary results from real life ASL Napoli 2 Nord experience. Eur Rev Med Pharmacol Sci. 2020;24:404047. doi:10.26355/eurrev_202004_20875

41. Schönrich G, Raftery MJ. The PD-1/PD-L1 axis and virus infections: a delicate balance. Front Cell Infect Microbiol. 2019;9:207. doi:10.3389/fcimb.2019.00207

42. Chen Y, Diao B, Wang C, et al. Reduction and functional exhaustion of $\mathrm{T}$ cells in patients with coronavirus disease 2019 (COVID-19) Front Immunol. 2020;11:827. doi:10.3389/fimmu.2020.00827

43. Jamilloux Y, Henry T, Belot A, et al. Should we stimulate or suppress immune responses in COVID-19? Cytokine and anti-cytokine interventions. Autoimmun Rev. 2020;19:102567. doi:10.1016/j. autrev.2020.102567

44. Villar J, Zhang H, Slutsky AS. Lung repair and regeneration in acute respiratory distress syndrome. Chest. 2019;155:587-594. doi:10.1016/j.chest.2018.10.022

45. Teuwen LA, Geldhof V, Pasut A, Carmeliet P. COVID-19: the vasculature unleashed. Nat Rev Immunol. 2020;20:389-391. doi:10.1038/s41577-020-0343-0

46. Yuksel H, Yilmaz O, Karaman M, et al. Vascular endothelial growth factor antagonism restores epithelial barrier dysfunction via affecting zonula occludens proteins. Exp Ther Med. 2015;10:362-368. doi:10.3892/etm.2015.2502

47. Pang J, Xu F, Aondio G, et al. Efficacy and tolerability of bevacizumab in patients with severe Covid-19. Nat Commun. 2021;12:814. doi:10.1038/s41467-021-21085-8

48. Li Y, Shi K, Qi F, et al. Thalidomide combined with short-term low-dose glucocorticoid therapy for the treatment of severe COVID-19: a case-series study. Int J Infect Dis. 2021;103:507-513. doi:10.1016/j.ijid.2020.12.023

49. Chen C, Qi F, Shi K, et al. Thalidomide combined with low-dose short-term glucocorticoid in the treatment of critical Coronavirus Disease 2019. Clin Transl Med. 2020;10:e35. doi:10.1002/ctm2.35

50. U.S. National Library of Medicine. MedlinePlus. Thalidomide. Available from: https://medlineplus.gov/druginfo/meds/a699032. html. Accessed March 19, 2021

51. McClendon J, Jansing NL, Redente EF, et al. Hypoxia-inducible factor $1 \alpha$ signaling promotes repair of the alveolar epithelium after acute lung injury. Am J Pathol. 2017;187:1772-1786. doi:10.1016/j. ajpath.2017.04.012

52. Drug Information Portal. U.S. National Library of Medicine. Alprostadil. Available from: https://druginfo.nlm.nih.gov/drugportal/ name/alprostadil. Accessed March 19, 2021.

53. Hashimoto S, Sanui M, Egi M, et al. The clinical practice guideline for the management of ARDS in Japan. J Intensive Care. 2017;5:50.

54. Russell JA, Ronco JJ, Dodek PM. Physiologic effects and side effects of prostaglandin E1 in the adult respiratory distress syndrome. Chest. 1990;97:684-692. doi:10.1378/chest.97.3.684

55. Richeldi L, Fernández Pérez ER, Costabel U, et al. Pamrevlumab, an anti-connective tissue growth factor therapy, for idiopathic pulmonary fibrosis (PRAISE): a Phase 2, randomised, double-blind, placebo-controlled trial. Lancet Respir Med. 2020;8:25-33. doi:10.1016/S2213-2600(19)30262-0

56. Xu J, Xu X, Jiang L, Dua K, Hansbro PM, Liu G. SARS-CoV-2 induces transcriptional signatures in human lung epithelial cells that promote lung fibrosis. Respir Res. 2020;21:182. doi:10.1186/s12931020-01445-6
57. Ito Y, Correll K, Schiel JA, Finigan JH, Prekeris R, Mason RJ. Lung fibroblasts accelerate wound closure in human alveolar epithelial cells through hepatocyte growth factor/c-Met signaling. $\mathrm{Am}$ J Physiol Lung Cell Mol Physiol. 2014;307:L94-L105. doi:10.1152/ ajplung.00233.2013

58. Hamilton JA. GM-CSF in inflammation. $J$ Exp Med. 2020;217: E20190945.

59. De Luca G, Cavalli G, Campochiaro C, et al. GM-CSF blockade with mavrilimumab in severe COVID-19 pneumonia and systemic hyperinflammation: a single-centre, prospective cohort study. Lancet Rheumatol. 2020;2:e465-e473. doi:10.1016/S2665-9913(20)30170-3

60. Temesgen Z, Assi M, Shweta FNU, et al. GM-CSF neutralization with lenzilumab in severe COVID-19 pneumonia: a case-cohort study. Mayo Clin Proc. 2020;95:2382-2394.

61. Lang FM, Lee KMC, Teijaro JR, et al. GM-CSF-based treatments in COVID-19: reconciling opposing therapeutic approaches. Nat Rev Immunol. 2020;20:507-514. doi:10.1038/s41577-020-0357-7

62. Rösler B, Herold S. Lung epithelial GM-CSF improves host defense function and epithelial repair in influenza virus pneumonia-a new therapeutic strategy? Mol Cell Pediatr. 2016;3:29. doi:10.1186/ s40348-016-0055-5

63. Herold S, Hoegner K, Vadász I, et al. Inhaled granulocyte/macrophage colony-stimulating factor as treatment of pneumonia-associated acute respiratory distress syndrome. $\mathrm{Am}$ $J$ Respir Crit Care Med. 2014;189:609-611. doi:10.1164/ rccm.201311-2041LE

64. Dranoff G, Crawford AD, Sadelain M, et al. Involvement of granulocyte-macrophage colony-stimulating factor in pulmonary homeostasis. Science. 1994;264:713-716. doi:10.1126/ science. 8171324

65. Kudlak KK, DeMuro JP, Hanna AF, Brem H. Acute lung injury following the use of granulocyte-macrophage colony-stimulating factor. Int J Crit Illn Inj Sci. 2013;3:279-281. doi:10.4103/22295151.124168

66. Li C, Zhao H, Wang B. Challenges for mesenchymal stem cell-based therapy for COVID-19. Drug Des Devel Ther. 2020;14:3995-4001. doi:10.2147/DDDT.S269407

67. Cavalli G, De Luca G, Campochiaro C, et al. Interleukin-1 blockade with high-dose anakinra in patients with COVID-19, acute respiratory distress syndrome, and hyperinflammation: a retrospective cohort study. Lancet Rheumatol. 2020;2:e325-e331. doi:10.1016/ S2665-9913(20)30127-2

68. Balkhair A, Al-Zakwani I, Al Busaidi M, et al. Anakinra in hospitalized patients with severe COVID-19 pneumonia requiring oxygen therapy: results of a prospective, open-label, interventional study. Int J Infect Dis. 2021;103:288-296. doi:10.1016/j.ijid.2020.11.149

69. Landi L, Ravaglia C, Russo E, et al. Blockage of interleukin-1 $\beta$ with canakinumab in patients with Covid-19. Sci Rep. 2020;10:21775. doi:10.1038/s41598-020-78492-y

70. Strohbehn GW, Heiss BL, Rouhani SJ, et al. COVIDOSE: a phase II clinical trial of low-dose tocilizumab in the treatment of noncritical COVID-19 pneumonia. Clin Pharmacol Ther. 2021;109:688-696. doi:10.1002/cpt.2117

71. Feld JJ, Kandel C, Biondi MJ, et al. Peginterferon lambda for the treatment of outpatients with COVID-19: a phase 2, placebo-controlled randomised trial. Lancet Respir Med. 2021: S2213-2600(20)30566-X. doi:10.1016/S2213-2600(20)30566-X.

72. Li H, Xiong N, Li C, et al. Efficacy of ribavirin and interferon- $\alpha$ therapy for hospitalized patients with COVID-19: a multicenter, retrospective cohort study. Int $J$ Infect Dis. 2021;104:641-648. doi:10.1016/j.ijid.2021.01.055

73. Baghaei P, Dastan F, Marjani M, et al. Combination therapy of IFN $\beta 1$ with lopinavir-ritonavir, increases oxygenation, survival and discharging of severe COVID-19 infected inpatients. Int Immunopharmacol. 2021;92:107329. doi:10.1016/j.intimp.2020.107329 
74. Bronte V, Ugel S, Tinazzi E, et al. Baricitinib restrains the immune dysregulation in patients with severe COVID-19. J Clin Invest. 2020;130:6409-6416. doi:10.1172/JCI141772

75. Kaplanski G, Bontemps D, Esnault P, et al. Combined Anakinra and Ruxolitinib treatment to rescue extremely ill COVID-19 patients: a pilot study. Autoimmun Rev. 2021;20:102726. doi:10.1016/j. autrev.2020.102726

76. Voysey M, Costa Clemens SA, Madhi SA, et al. Single-dose administration and the influence of the timing of the booster dose on immunogenicity and efficacy of ChAdOx1 nCoV-19 (AZD1222) vaccine: a pooled analysis of four randomised trials. Lancet. 2021. doi:10.1016/S0140-6736(21)00432-3

77. Zhang Y, Zeng G, Pan H, et al. Safety, tolerability, and immunogenicity of an inactivated SARS-CoV-2 vaccine in healthy adults aged 18-59 years: a randomised, double-blind, placebo-controlled, Phase 1/2 clinical trial. Lancet Infect Dis. 2021;21:181-192. doi:10.1016/ S1473-3099(20)30843-4
78. Richmond $\mathrm{P}$, Hatchuel L, Dong M, et al. Safety and immunogenicity of S-Trimer (SCB-2019), a protein subunit vaccine candidate for COVID-19 in healthy adults: a phase 1, randomised, double-blind, placebo-controlled trial. Lancet. 2021;397:682-694. doi:10.1016/ S0140-6736(21)00241-5

79. Chen P, Nirula A, Heller B, et al. SARS-CoV-2 neutralizing antibody LY-CoV555 in outpatients with Covid-19. $N$ Engl J Med. 2021;384:229-237. doi:10.1056/NEJMoa2029849

80. Mastellos DC, Pires da Silva BGP, Fonseca BAL, et al. Complement C3 vs C5 inhibition in severe COVID-19: early clinical findings reveal differential biological efficacy. Clin Immunol. 2020;220:108598. doi:10.1016/j.clim.2020.108598

\section{Publish your work in this journal}

Drug Design, Development and Therapy is an international, peerreviewed open-access journal that spans the spectrum of drug design and development through to clinical applications. Clinical outcomes, patient safety, and programs for the development and effective, safe, and sustained use of medicines are a feature of the journal, which has also been accepted for indexing on PubMed Central. The manuscript management system is completely online and includes a very quick and fair peer-review system, which is all easy to use. Visit http://www. dovepress.com/testimonials.php to read real quotes from published authors. 